\title{
Erratum
}

\section{Erratum to "Seasonal Regional Differentiation of Human Thermal Comfort Conditions in Algeria"}

\author{
Salah Sahabi Abed $\mathbb{D}^{1}$ and Andreas Matzarakis $\mathbb{D}^{2}$ \\ ${ }^{1}$ Office National de la Météorologie, Centre Climatologique National, 1, Av. Mohamed Khemisti, BP 153, Dar El Beïda, Algiers, Algeria \\ ${ }^{2}$ Research Center Human Biometeorology, Deutscher Wetterdienst, Stefan-Meier-Str. 4, 79104 Freiburg im Breisgau, Germany \\ Correspondence should be addressed to Salah Sahabi Abed; salah_sahabi@yahoo.com \\ Received 20 March 2018; Accepted 26 March 2018; Published 15 April 2018 \\ Copyright (C) 2018 Salah Sahabi Abed and Andreas Matzarakis. This is an open access article distributed under the Creative \\ Commons Attribution License, which permits unrestricted use, distribution, and reproduction in any medium, provided the \\ original work is properly cited.
}

In the article titled "Seasonal Regional Differentiation of Human Thermal Comfort Conditions in Algeria" [1], there was an error in Conclusion where the sentence "The most important components of thermal perception are humidity and wind" should be removed as it was repeated.

\section{References}

[1] S. S. Abed and A. Matzarakis, "Seasonal regional differentiation of human thermal comfort conditions in Algeria," Advances in Meteorology, vol. 2017, Article ID 9193871, 14 pages, 2017. 

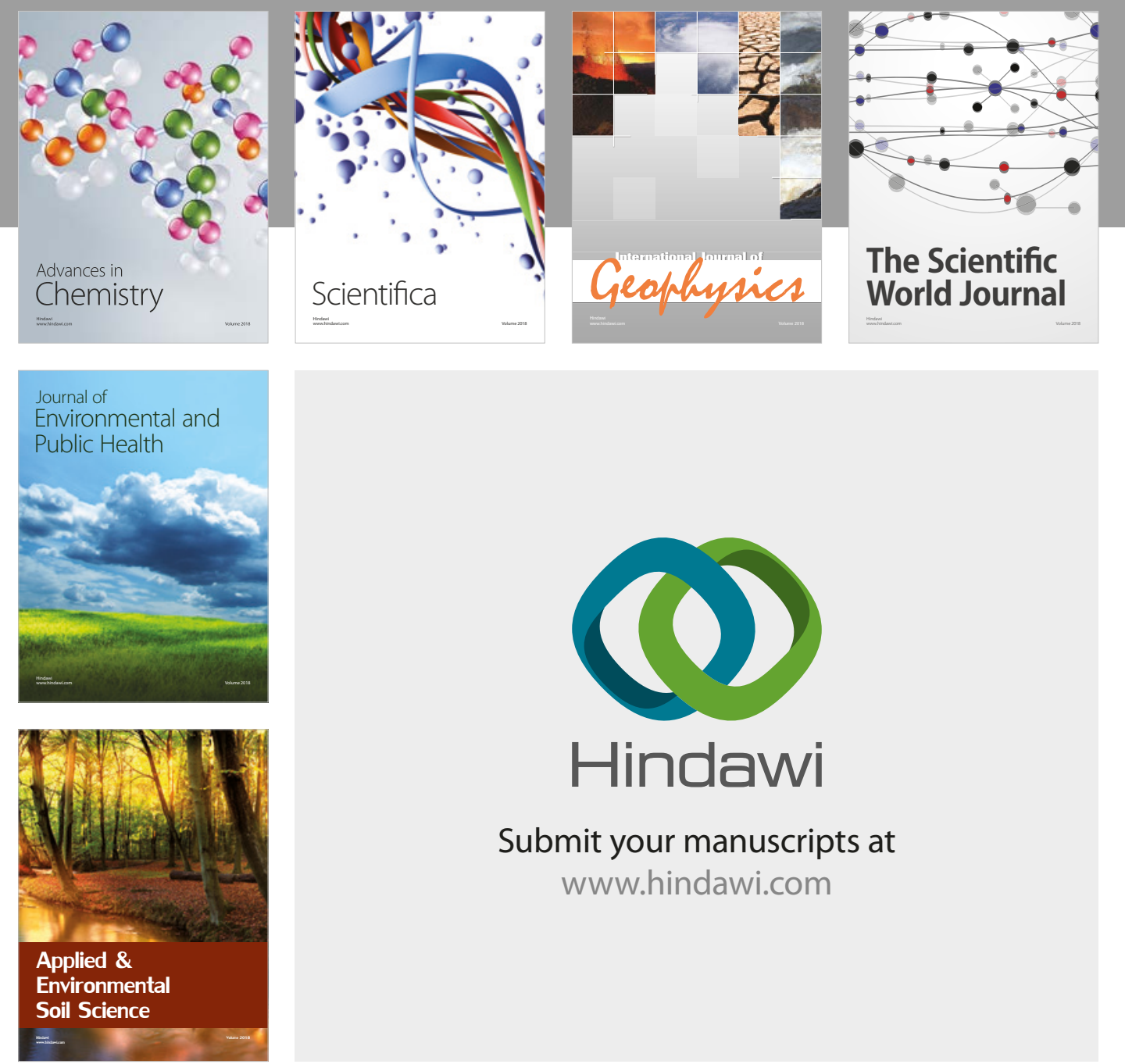

The Scientific

\section{World Journal}
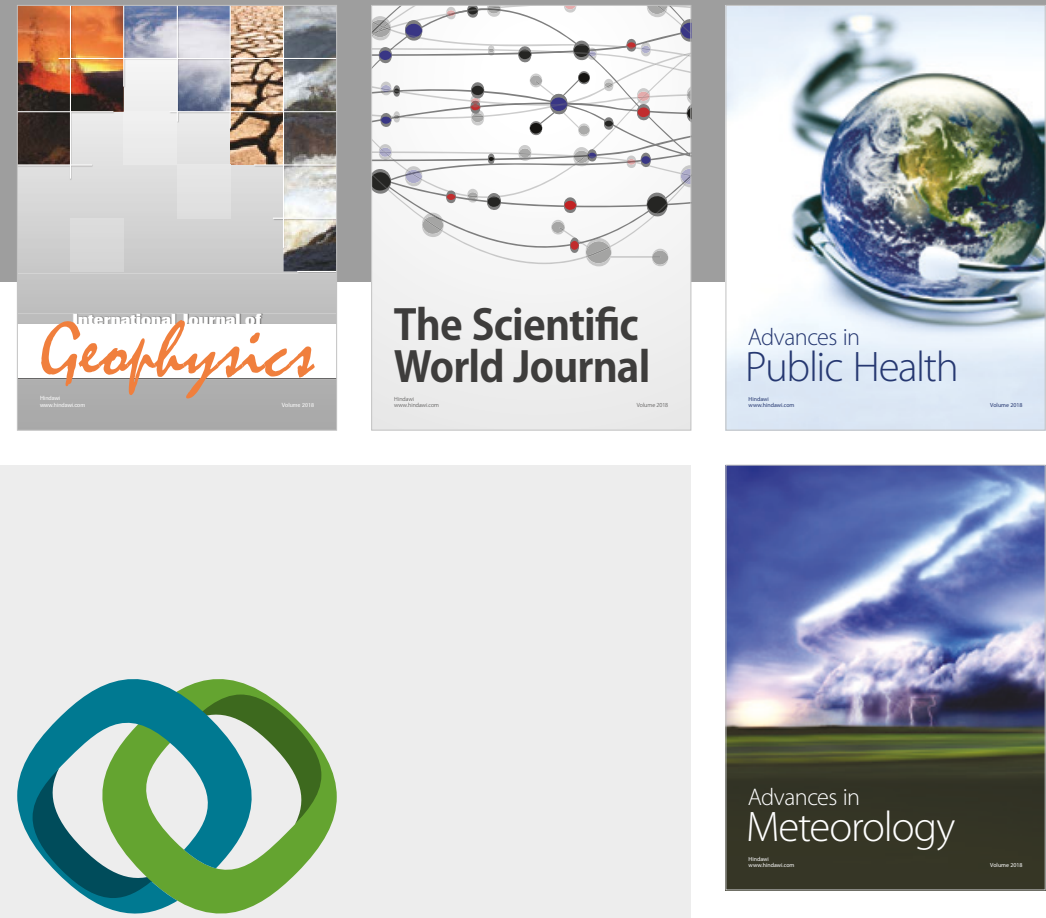

Advan

Public Health

\section{Hindawi}

Submit your manuscripts at

www.hindawi.com
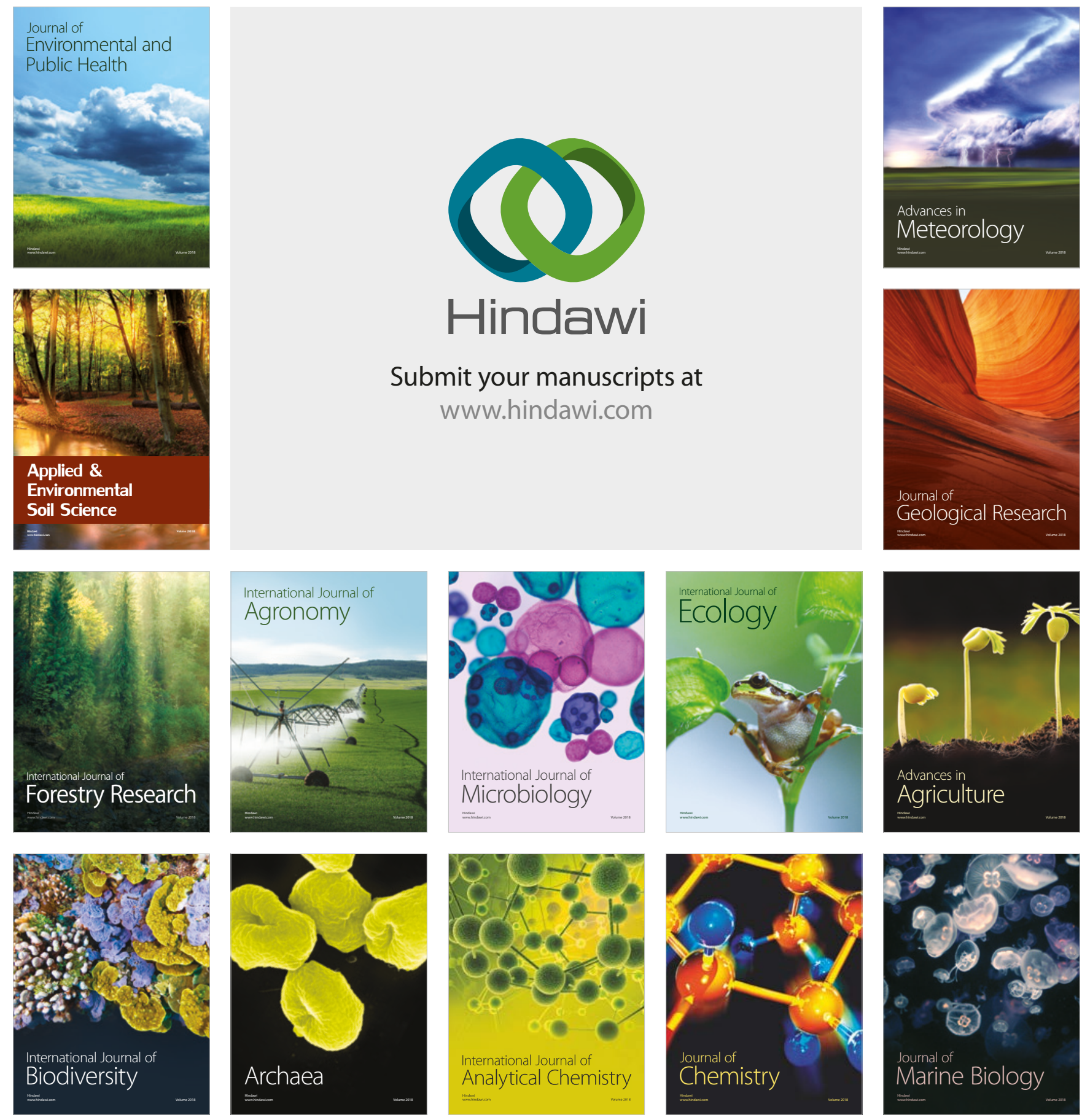